\title{
OUTROS TEMAS \\ Discurso da Matemática Específica para Ensinar: a arte de governar
}

\author{
Jaqueline de Souza Pereira Grilo' \\ Jonei Cerqueira Barbosa"
}

'Universidade Estadual de Feira de Santana (UEFS), Feira de Santana/BA-Brasil "Universidade Federal da Bahia (UFBA), Salvador/BA - Brasil

RESUMO - Discurso da Matemática Específica para Ensinar: a arte de governar. $\mathrm{O}$ artigo discute como o discurso da Matemática específica para ensinar tem proposto a condução da conduta de professores(as) de Matemática. Trata-se de um ensaio teórico decorrente de uma problematização foucaultiana que incidiu sobre estudos que tratam do Conhecimento Matemático para o Ensino, do Conhecimento Especializado do Professor de Matemática e da Matemática para o Ensino. Esse discurso põe em exercício diferentes tipos de poder, mobilizando estratégias e táticas a fim de acionar a tecnologia nomeada Tecnologia da Especificidade Matemática. Os resultados sugerem que as condutas disponibilizadas por esse discurso transitam entre a lógica individual e disciplinar à lógica governamental.

Palavras-chave: Educação Matemática. Discurso. Poder. Governamentalidade.

ABSTRACT - Specific Mathematics for Teaching Discourse: the art of governing. The article discusses how the Mathematics discourse specific to teaching has proposed the conduct of mathematics teachers. It is a theoretical essay resulting from a Foucaultian problematization that focused on studies dealing with Mathematical Knowledge for Teaching, the Specialized Knowledge of the Math Teacher and Mathematics for Teaching. This discourse puts into practice different types of power, mobilizing strategies and tactics in order to activate the technology named Technology of Mathematical Specificity. The results suggest that the behaviors made available by this discourse move between individual and disciplinary logic to government logic.

Keywords: Math Education. Discourse. Power. Governmentality.

Educação \& Realidade, Porto Alegre, v. 46, n. 1, e98349, 2021.

http://dx.doi.org/10.1590/2175-623698349 


\section{Introdução}

Na área de Educação Matemática, diferentes discursos têm circulado no intuito de argumentar que, para ensinar Matemática, um professor deveria mobilizar conhecimentos matemáticos específicos para o ensino (Ball; Bass, 2003; Ball; Thames; Phelps, 2008; Barwell, 2013; Carrillo; Climent; Contreras; Muñoz-Catalán, 2013; Davis; Renert, 2014). O termo discurso é empregado em conformidade com a teorização foucaultiana, que extrapola a noção de uma simples combinação de palavras ou frases referindo-se a um conjunto de práticas que designam as coisas ${ }^{1}$ de que falam. Desse modo, um discurso não se reduz a um ato de fala, não apenas representa a coisa da qual se fala, mas a constitui (Foucault, 2014a; 2016).

Identificamos o discurso da Matemática específica para ensinar circulando em estudos da área sobre diferentes denominações, dentre as quais destacamos: o Mathematics Knowledge for Teaching (MKT) ou Conhecimento Matemático para o Ensino (CME), Mathematics Teacher's Specialized Knowledge (MTSK) ou Conhecimento Especializado do Professor de Matemática (CEPM) e a Mathematics for Teaching (MfT) ou Matemática para o Ensino (MpE), dada a ampla divulgação dos mesmos (Hoover; Mosvold; Ball; Lai, 2016).

Em estudo anterior (Grilo; Barbosa; Maknamara, 2020), sugerimos que discursos que circulam nesses estudos podem ser organizados em dois grupos: i) discursos cognitivo-representacionais, para os quais o(a) professor(a) é capaz de descompactar, conectar, antecipar, articular, compreender e provar ideias matemáticas de forma associada às demandas específicas do ensino. Portanto, escolhe atividades adequadas às demandas do ensino, é crítico de materiais didáticos e curriculares, é eficiente, regente das tarefas vinculadas ao ensino e atento às desigualdades; e, ii) discursos sócio discursivos², para os quais o(a) professor(a) é regulado pelos princípios da prática pedagógica, flexível, explorador de oportunidades e formulador de conceitos matemáticos de acordo com o contexto do qual participa. Por ser integrante de uma prática social, constitui-se coletivamente, logo, é evolutivo, participativo e engajado e sua prática resulta de um repertório coletivo e instável.

Este modo de organizá-los visa demarcar que existem diferenças entre as afiliações epistemológicas que os embasam teoricamente, sem desconsiderar a possibilidade de que eles se influenciam mutuamente, independentemente das terminologias adotadas. Neste sentido, adotamos a noção de Matemática específica para ensinar na tentativa de capturar a variabilidade de discursos do CME, do CEPM e do MpE em uma única expressão. Assim, quando usamos a frase discurso da Matemática específica para ensinar estamos nos referindo a uma formação discursiva que reúne os discursos do CME, do CEPM e do MpE. Uma formação discursiva é assegurada por um conjunto de relações que se estabelece entre instâncias e objetos do discurso, considerando suas condições históricas, suas regularidades e dispersões (Foucault, 2016). 
Esses discursos têm sido amplamente divulgados entre educadores matemáticos em diferentes países, por meio de investigações que se apoiam em itens que advogam para si a tarefa de refletir sobre situações reais enfrentadas por professores ao ensinar Matemática. A título de exemplo, citamos um dos projetos do grupo de pesquisadores liderado por Deborah Loewenberg Ball ${ }^{3}$, o Learning Mathematics for

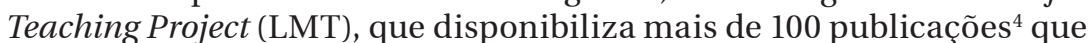
tratam: de medidas que o grupo utiliza para estudar (Schilling; Blunk; Hill, 2007); do que acreditam ser a estrutura do conhecimento matemático do professor (Hill; Schilling; Ball, 2004); de como os professores aprendem o conhecimento matemático para o ensino (Hill; Ball, 2004); de como o conhecimento do professor se relaciona com o desempenho matemático dos alunos (Hill; Rowan; Ball, 2005); das relações entre conhecimento do professor, currículo e qualidade do ensino (Charalambous; Hill, 2012), dentre outros.

O LMT é apontado como um dos pilares de um outro projeto intitulado Teacher Education and Development Study in Mathematics (TEDS-M). Este, conduzido sob a égide da International Association for the Evaluation of Educational Achievement (IEA), foi concebido para fornecer informações que pudessem ser utilizadas na elaboração de políticas e práticas de formação de professores de Matemática (Tatto, 2013). Segundo Tatto (2013), o TEDS-M envolveu dezessete países ${ }^{5}$, se configurando como o primeiro estudo transnacional desenvolvido com o objetivo de fornecer dados sobre o conhecimento que os futuros professores adquirem durante a formação inicial, focalizando o conhecimento do conteúdo matemático e o conhecimento pedagógico do conteúdo matemático. As medidas elaboradas e utilizadas por esses projetos decorrem do refinamento realizado por Ball, Thames e Phelps (2008) da proposta de Shulman (1987) para descrever o conhecimento profissional de professores.

Este refinamento é fruto da tentativa de pesquisadores em desenvolver a noção de Mathematical Knowledge for Teaching (MKT) que visa enfatizar a importância do conhecimento matemático que é específico do ensino, um conhecimento matemático que, segundo Hoover, Mosvold, Ball e Lai (2016), é diferente da Matemática tipicamente ensinada na escola (embora inclua conhecer a Matemática ensinada aos alunos) e da Matemática necessária por outros profissionais que não são professores. Na proposta de Ball, Thames e Phelps (2008), o Conhecimento do Conteúdo é subdividido em: Conhecimento Comum do Conteúdo, Conhecimento Especializado do Conteúdo e Conhecimento do Conteúdo no Horizonte. Do mesmo modo, o Conhecimento Pedagógico do Conteúdo, é subdividido em: Conhecimento do Conteúdo e Alunos, Conhecimento do Conteúdo e Ensino e Conhecimento do Conteúdo e do Currículo.

Neste cenário, outros discursos aparecem em disputa, seja para propor uma ênfase sobre o Conhecimento Especializado do Conteúdo, tal que a natureza especializada definiria todo o conhecimento em respeito ao ensino de Matemática (Carrillo; Climent; Contreras; Muñoz- 
Catalán, 2013), seja para propor a não dicotomização entre, por exemplo, o conhecimento do conteúdo matemático e o conhecimento pedagógico do conteúdo matemático (Huillet, 2009; Pournara et al., 2015; Tatto; Burn; Menter; Mutton; Thompson, 2018). Há ainda discursos que desafiam a proposta de Ball, Thames e Phelps (2008) por considerá-la extremamente focada no indivíduo e optam por apresentar o conhecimento matemático para ensinar sob uma perspectiva social, coletiva, emergente (Adler; Hulliet, 2008; Barwell, 2013; Davis; Rennert, 2014).

Mesmo não integrando o TEDS-M, países como Arábia Saudita, África do Sul, Coréia do Sul, Brasil, dentre outros, não ficaram à margem dessas discussões. Entre esses países, é possível identificarmos investigações que utilizam os itens propostos pelo LMT (Haroun; Ng; Abdelfattah; Alsalouli, 2016; Kwon; Thames; Pang, 2012), assim como há aqueles que adotam uma perspectiva mais social para a investigação sobre o conhecimento matemático para ensinar (Pournara et al., 2015; Davis; Rennert, 2014; Santos; Barbosa, 2016).

Diante do alcance e de como esses discursos têm influenciado a Educação Matemática, consideramos oportuno, inspirados em Michel Foucault, problematizar como esses discursos têm proposto a condução da conduta de professores de Matemática. Entendemos que a condução da conduta são as práticas de controle sobre a vida dos sujeitos, sejam elas no âmbito da vida individual ou coletiva, que visam estabelecer um campo possível de ação. Neste sentido, desenvolvemos um ensaio teórico que, segundo Meneghetti (2011), exige reflexões profundas e minuciosas para a compreensão das coisas. As nossas reflexões incidiram sobre estudos nos quais discursos do CME, CEPM e MpE circulam e que se encontram amplamente divulgados em periódicos da Educação Matemática, como descrito anteriormente.

\section{O Poder se Mostra em Exercício}

Ao buscarmos investigar a condução da conduta de professores(as) de Matemática, o nosso olhar esteve voltado para os efeitos desses discursos em suas possíveis ações. Isso nos levou a mobilizar a temática do governo (Foucault, 1989; 1999a; 2008) como um grande guarda-chuva, no sentido de que ela absorve a chuva de exercícios de poder que são postos em funcionamento por discurso da Matemática específica para ensinar.

O poder se mostra em ação ao ser exercido, portanto, não se possui, não se ganha e também não se perde. Se o poder não emana de um centro, ele é tomado "[...] como uma rede produtiva que atravessa todo o corpo social muito mais do que uma instância negativa que tem por função reprimir" (Foucault, 1989, p. 8). Assim, o poder não se aplica a um indivíduo ou é por ele aplicado, o poder os atravessa no intuito de dirigir as condutas.

Quando Michel Foucault se propôs a investigar a temática do governo, ele voltou-se para identificar e descrever as tecnologias de poder voltadas para a condução de si e dos outros. A partir de algumas de suas 
obras (Foucault, 1999a; 2008), é possível compreender que o termo tecnologia foi utilizado por Michel Foucault “[...] como um sistema de práticas investido de uma racionalidade estratégica” (Villadsen, 2014, p. 3).

Para Castro (2016, p. 412), “[...] estudar as práticas como técnicas ou tecnologia consiste em situá-las em um campo que se define pela relação entre meios (táticas) e fins (estratégia)”. Logo, descrever uma tecnologia consiste em situá-la em termos de estratégias e táticas. A estratégia é o meio utilizado para fazer funcionar ou para manter uma tecnologia de poder, visa o treinamento rotinizado que molda os indivíduos a partir de objetivos previamente planejados e a tática é aquilo que põe a estratégia em funcionamento. De acordo com Maknamara e Paraíso (2013, p. 49), “[...] enquanto a estratégia é meticulosamente arquitetada [...], a tática é oportunisticamente acionada”. Foucault (2014b) ilustra esses conceitos considerando o âmbito militar para o qual a estratégia pode ser compreendida como uma maneira de conduzir uma guerra e a tática seria a existência do exército como um princípio para manter a ausência de guerras na sociedade.

O uso da palavra governo não deve ser confundido com o uso que é dado à palavra atualmente, enquanto governo de um Estado; governam-se corpos, população. A população é um personagem político que surge no século XVIII (Foucault, 2008), como um novo sujeito coletivo, “[...] um novo corpo: corpo múltiplo, corpo com inúmeras cabeças, se não infinito pelo menos necessariamente numerável” (Foucault, 1999a, p. 292).

No presente estudo, consideramos o conjunto de professores de Matemática como a população para a qual o discurso da Matemática específica para ensinar estrutura um campo possível de ações. Esse discurso tem fornecido informações que subsidiam tanto as políticas públicas educacionais, seja a nível da escolarização básica (Hill, 2007) ou a nível da formação de professores (Hill; Ball, 2004), quanto as relações pedagógicas que ocorrem em sala de aula (Charalambous; Hill, 2012). Dada a sua amplitude, tanto em termos do que subsidiam ou podem a vir a subsidiar, quanto em termos de abrangência territorial, eles colocam em operação práticas de governo que visam estruturar o campo possível de ações ao conjunto de professores de Matemática, transitando entre a lógica individual e disciplinar até a lógica governamental.

Ao tentar explicitar a passagem das práticas de poder individualizantes para práticas massificantes, Michel Foucault cunhou o conceito de gouvernementalité que, segundo Fimyar (2009), traduz o esforço de criar sujeitos governáveis através de técnicas de controle, normalização e moldagem das condutas das pessoas. Para Veiga-Neto (2002), a palavra governamentalidade seria a tradução mais adequada para gouvernementalité. Assim, governamentalidade são práticas de governo que têm na população seu objeto e que pretendem estruturar o campo possível de ações de si e dos outros (Foucault, 2008).

Ao tomar o conceito de governamentalidade, Michel Foucault não desconsidera que esses poderes continuam agindo sobre os corpos in- 
dividualmente com a pretensão de conduzir condutas. Assim, no intuito de desvelarmos como o discurso da Matemática específica para ensinar tem proposto a condução da conduta de professores de Matemática, analisamos diferentes tipos de poder postos em funcionamento por esse discurso. Para isso, apoiamo-nos na genealogia sobre a temática do governo realizada por Michel Foucault, que nega a possibilidade de um centro de poder, geralmente representado pelo Estado nas teorias clássicas sobre governo, e volta-se para mostrar como o poder está diluído, atravessando toda estrutura social, na defesa de que "[...] o poder está em toda parte; não porque englobe tudo, e sim porque provém de todos os lugares" (Foucault, 1999b, p. 89).

\section{O Exercício do Poder: da lógica disciplinar à governamental}

Ao investigar a temática do governo, Foucault (1989; 1999a; 2008) identificou e nominou diferentes tipos de poder, dos quais destacamos: poder soberano, poder pastoral, poder disciplinar e biopoder. Esses poderes foram identificados em diferentes tempos históricos, mas ainda hoje podem coexistir agindo mutuamente sobre os corpos e sobre as populações.

Iniciaremos nossa digressão pelo poder soberano que se pauta na existência da figura de um soberano e seus súditos. Segundo Foucault (1999a), o soberano, a fim de defender o seu território ou a si mesmo, detém o direito sobre a vida e a morte dos seus súditos. Isto nos permite perguntar, por exemplo, porque o estudo desenvolvido por Shulman (1987), que pretendia revolucionar o modo como o conhecimento do professor tinha sido pesquisado até então, não foi suficiente para dar conta do conhecimento requerido ao professor de Matemática? Quão soberana é a Matemática que leva Ball, Thames e Phelps (2008) a estabelecerem domínios específicos no mapa conceitual do conhecimento de professores elaborado por Lee Shulman, mesmo reconhecendo a importância de suas ideias sobre o conhecimento do conteúdo e o conhecimento pedagógico do conteúdo no ensino? Os próprios autores esboçam uma possível resposta a essas perguntas:

Nossa hipótese é que as oportunidades dos professores de aprender matemática para o ensino poderiam ser mais bem ajustadas se pudéssemos identificar esses tipos [de conhecimento] de forma mais clara. Se o conhecimento matemático necessário para o ensino é, de fato, multidimensional, então a educação profissional poderia ser organizada para ajudar os professores a aprenderem a gama de conhecimentos e habilidades de que necessitam de maneiras focadas. Se, no entanto, o conhecimento matemático necessário para o ensino é basicamente o mesmo que a capacidade matemática geral, então seria desnecessário discriminar as oportunidades de aprendizagem profissional. Com base em nossa análise das demandas matemáticas do ensino, supomos que o conhecimento de conteúdo de Shulman poderia ser subdividido em CCK 
[conhecimento comum do conteúdo] e conhecimento especializado do conteúdo e seu conhecimento pedagógico de conteúdo poderia ser dividido em conhecimento de conteúdo e estudantes e conhecimento de conteúdo e ensino (Ball; Thames; Phelps, 2008, p. 399).

Assim, essa Matemática que é específica para o ensino teria um lugar de destaque, exercendo um poder soberano que atravessa os seus súditos, os professores e professoras de Matemática. Portanto, o território a ser governado é aquele que envolve as práticas docentes, sejam em cursos de formação inicial ou continuada ou as práticas pedagógicas estabelecidas nos espaços escolares. O sacrifício dos súditos é identificado no sentido de fazer morrer uma prática docente baseada em uma Matemática que não é específica para o ensino, permitindo deixar viver uma prática docente que dê conta de tais especificidades.

O poder soberano exercido pela Matemática, na condição de um corpo de conhecimento científico que precisa ser esquadrinhado antes de ser deslocado para fins de ensino, atravessa todos aqueles que lidam com ela. Assim, como nos sugere Foucault (1989), olhamos para esse poder não como localizado em um centro; mas, como uma rede, a partir de suas ramificações ao atravessar esse corpo múltiplo que são os professores de Matemática.

A categorização proposta por Ball, Thames e Phelps (2008) (Figura 1) evidencia que o Conhecimento Matemático para o Ensino requer, dentre outros domínios, um Conhecimento Especializado do Conteúdo que se diferencia da capacidade matemática geral que seria expressa por um Conhecimento Comum do Conteúdo.

Figura 1 - Domínios do Conhecimento Matemático para o Ensino

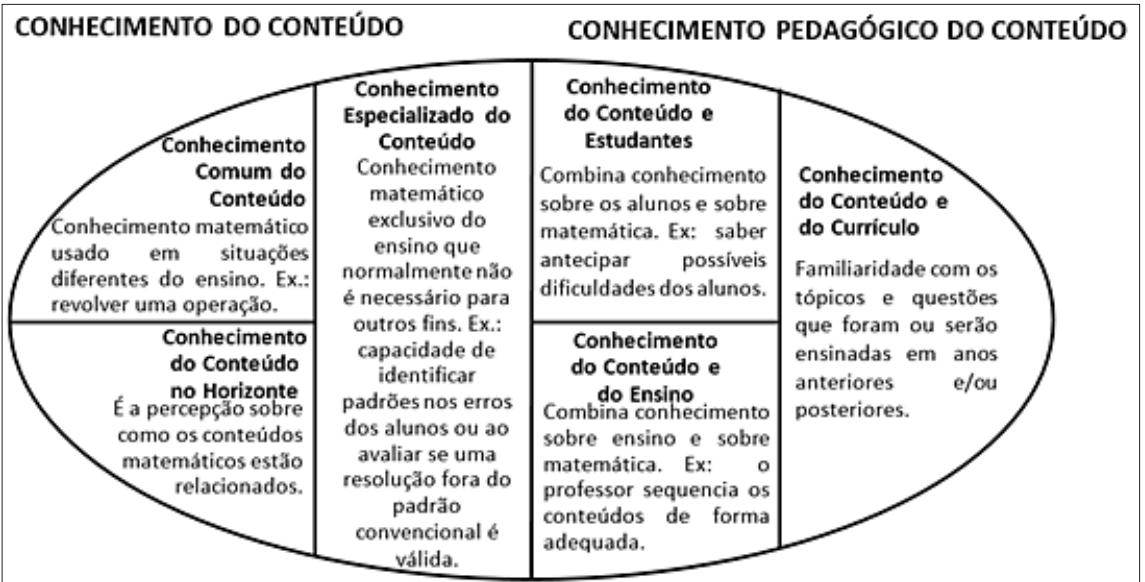

Fonte: Adaptado de Ball; Thames; Phelps (2008).

Esses domínios estão descritos em grande parte dos estudos onde circulam discursos cognitivo-representacionais sobre o conhecimento matemático específico para ensinar (Barwell, 2013). Para Ball, Thames 
e Phelps (2008), o Conhecimento Matemático para o Ensino é multidimensional e uma vez identificados os tipos de conhecimento requeridos para ensinar, os cursos de formação de professores poderiam ser organizados para ajudar os professores a aprenderem a gama de conhecimentos e habilidades de que necessitam para ensinar.

Outros estudos propõem que o conhecimento dos professores é especializado (Carrillo; Climent; Contreras; Muñoz-Catalán, 2013; Moriel Junior; Wielewski; 2017) e configuram a noção de Conhecimento Especializado de Professores de Matemática. Como é possível observar na Figura 2, o CEPM também se organiza em domínos e subdomínios que focalizariam demandas relacionadas ao ensino de Matemática em particular. Desse modo, nesses discursos não basta reconhecer que para ensinar Matemática o professor precisa dispor de um Conhecimento Especializado do Conteúdo: é preciso conduzi-lo de modo que ele se desloque entre um tipo de conhecimento e outro.

\section{Figura 2 - Domínios do Conhecimento Especializado de Professores de Matemática}

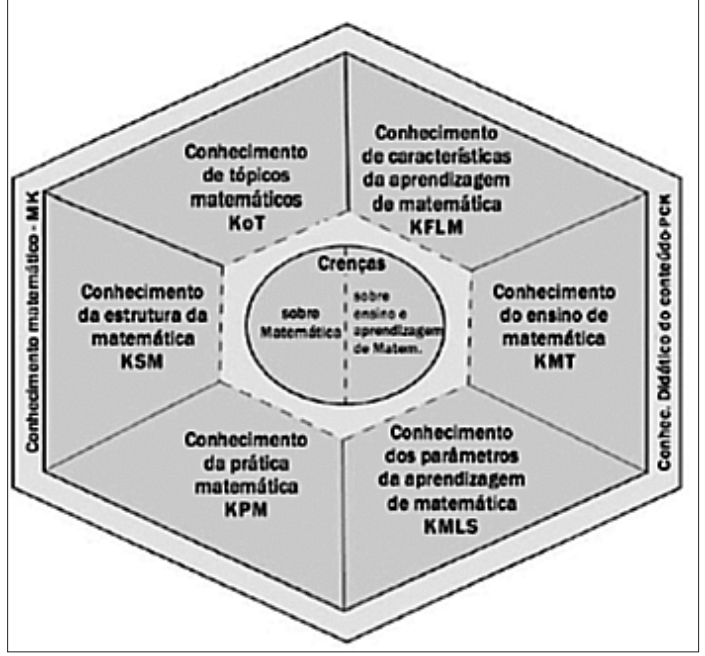

Fonte: Moriel Junior; Wielewski (2017).

Mesmo apoiados em perspectivas epistemológicas distintas, de maneira similar, os discursos sócio discursivos da Matemática específica para ensinar também se voltam para os modos de deslocamento, não mais do professor como corpo individual, mas da população de professores. O interesse está em observar como professores, na condição de um corpo com inúmeras cabeças, se movem entre as ênfases (Figura 3) que constituiriam as formas de comunicar um determinado conceito matemático. 


\section{Figura 3 - Metáfora Visual para Descrever as Relações entre} Ênfases do Estudo de Conceito

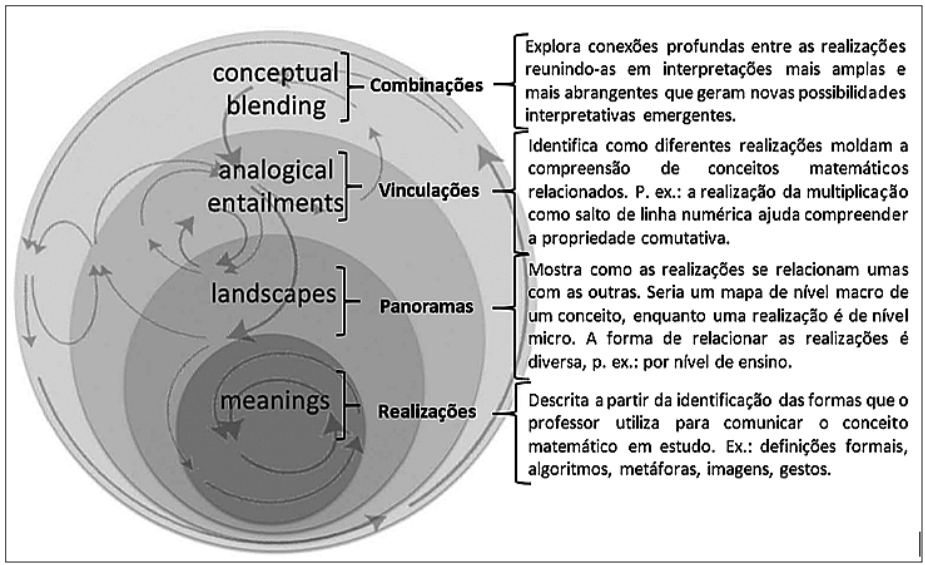

Fonte: Adaptado de Davis; Renert (2014, p. 57).

Apoiados na teoria da complexidade, Davis e Renert (2014) compreendem que as ênfases (realizações, panoramas, vinculações e combinações) estariam mais focadas no conteúdo matemático real do ensino. Ainda segundo os autores, essas ênfases não ocorrem de forma linear e nem como etapas; seriam co-implicadas, emergentes e em evolução, o que exigiria compromissos participativos, coletivos e contínuos dos professores.

A estratégia utilizada para colocar em exercício o poder soberano é fazer viver uma Matemática que é específica para o ensino a fim de deixar morrer uma Matemática que não é específica para ensinar, na defesa de que existe um conhecimento matemático que é específico para o ensino de Matemática. Junto a essa estratégia é acionada a tática da diferenciação que pretende desnudar categorias do conhecimento profissional proposta por Shulman (1987) no sentido de tornar explícita a diferença entre a Matemática a ser disponibilizada para o professor e a Matemática requerida por outros profissionais. Ambos os discursos, cognitivo-representacionais e sócio discursivos, operam no sentido de fazer morrer práticas pedagógicas baseadas em uma Matemática que não é específica para o ensino, a fim de deixar viver práticas que se estabelecem por meio de uma Matemática específica para ensinar.

Observamos, entretanto, que outras formas de poder são postas em funcionamento por esses discursos transitando entre a expressão de um poder individualizante e disciplinar até a lógica massificante, que fazem os professores viverem conforme suas regras. O poder disciplinar se volta para controlar a multiplicidade, organizá-la de modo a utilizá-las ao máximo; “[...] define como se pode ter o domínio sobre o corpo dos outros, não simplesmente para que façam o que se quer, mas para que operem como se quer" (Foucault, 2014b, p. 135). O poder disciplinar "[...] toma os indivíduos ao mesmo tempo como objetos e como instrumentos de seu exercício" (Foucault, 2014b, p. 167). 
Em busca desse adestramento dos corpos, o poder disciplinar recorre à disciplina. A disciplina se revela em "[...] métodos que permitem o controle minucioso das operações do corpo, que realizam a sujeição constante de suas forças e lhes impõem uma relação de docilidadeutilidade" (Foucault, 2014b, p. 135). A disciplina age sobre os corpos; é sutil, devendo o seu sucesso ao uso de instrumentos simples: o olhar hierárquico e a sanção normalizadora, além do exame que resulta da combinação dos anteriores. Voltemos nosso olhar sobre o exame.

O exame "[...] é um controle normalizante, uma vigilância que permite qualificar, classificar e punir. Estabelece sobre os indivíduos uma visibilidade através da qual eles são diferenciados e sancionados" (Foucault, 2014b, p. 181). O exame inverte a lógica da visibilidade do poder, tornando-o cada vez mais invisível à medida em que é mais insidioso; disponibiliza um campo documentário de registros de uma série de traços individuais que permitem classificar, categorizar e fixar normas que se tornam homogeneizantes.

Ao nos voltarmos para os discursos cognitivo-representacionais, identificamos o uso do exame como instrumento do exercício do poder disciplinar. Projetos como o Learning Mathematics for Teaching Project $(\mathrm{LMT})^{6}$ e o Teacher Education and Development Study in Mathematics (TEDS-M) (Tatoo, 2013) utilizam a técnica do exame por meio da elaboração/aplicação/refinamento de instrumentos que são aplicados em larga escala a professores e estudantes com vistas a um controle minucioso de seus corpos. Esses instrumentos são utilizados para examinar a estrutura do conhecimento matemático do professor (Ní Ríordáin; Paolucci; O’ Dwyer, 2017); o modo como esses professores aprendem esse conhecimento para fins de ensino (Mosvold; Fauskanger, 2013); como podem relacioná-los com o desempenho matemático dos estudantes (Delaney, 2012; Tchoshanov, 2011); refinar os instrumentos de avaliação (Phelps; Kelcy; Jones; Liu, 2016), dentre outros fins.

Para exemplificarmos como o uso do exame, como um instrumento do poder disciplinar, é posto em exercício por discursos cognitivo-representacionais, apresentamos abaixo o resumo do artigo de Kwon, Thames e Pang (2012).

Este artigo examina os desafios na adaptação das medidas do conhecimento matemático para o ensino (MKT) desenvolvidas nos Estados Unidos para uso na Coréia. Depois de uma análise inicial das questões dos candidatos em relação ao 'ajuste' dos itens ao contexto coreano - se os itens eram conhecidos, autênticos e realistas, [...] - adaptamos e administramos um instrumento desenvolvido pelo projeto Learning Mathematics for Teaching com 93 professores coreanos e realizamos entrevistas de acompanhamento com nove professores. Com base na análise desses dados, realizamos uma segunda rodada de revisão e, em seguida, administramos o teste revisado a 101 professores coreanos. Os resultados mostraram que pequenas modificações que foram feitas para aumentar o ajuste muitas vezes aumentaram o desempenho dos 
professores nos itens, como esperado, mas o impacto das mudanças foi às vezes difícil de interpretar. Para vários itens, as modificações introduziram problemas de validade imprevistos. $\mathrm{O}$ artigo discute as dinâmicas que surgem ao fazer mudanças nos itens do MKT - em particular, a tensão na modificação de itens para aumentar o ajuste a contextos educacionais específicos, mantendo a validade (Kwon; Thames; Pang, 2012).

Do exposto neste estudo, vemos como o exame é utilizado para o controle dos corpos quando toma os professores como objeto de estudo (ao responderem os itens) e, ao mesmo tempo, como instrumento de exercício de poder (ao fornecerem informações que permitem o ajuste de tais itens). Na lógica do exame, os professores estão cada vez mais visíveis à medida em que o poder disciplinar é mais insidioso disponibilizando registros sobre a Matemática específica para ensinar. Esses registros, primeiramente, são individuais, mas permitem classificar, categorizar e fixar normas que se tornam homogeneizantes.

Os discursos sócio discursivos se mostram contrários à forma como o exame é utilizado por discursos cognitivo-representacionais como se observa no estudo de Davis e Renert:

\begin{abstract}
A ênfase da pesquisa contemporânea em identificar e medir o que cada professor pode articular explicitamente é, a nosso ver, simplesmente inadequada - tanto como ferramentas para avaliar o que os professores realmente sabem como como meios para apoiar o desenvolvimento do corpo vibrante do conhecimento da M4T (Davis; Renert, 2014, p. 116).
\end{abstract}

Entretanto, isso não significa que eles não coloquem em exercício o poder disciplinar fazendo uso do exame como um instrumento de controle dos professores. O que esses discursos propõem é o uso de

[...] análises mais refinadas do que as avaliações em larga escala, em grande parte porque muitos dos aspectos mais importantes do conhecimento dos professores simplesmente não estão disponíveis para uma avaliação explícita e imediata. Eles são tácitos e só podem emergir através da participação em explorações coletivas, como estudos do conceito.

Dito isso, nos engajamos em algumas estratégias pragmáticas para aumentar nossa base populacional. Por exemplo, o programa de formação de professores da University of Calgary foi reestruturado para que todos os candidatos a professores - nos níveis básico e secundário - declarassem uma especialização. Para aqueles que optam por uma especialização em matemática, um dos principais componentes de sua experiência de dois anos (quatro semestres) é o estudo do conceito. Além disso, a Faculdade de Educação oferece uma turma de mestrado de educação de dois anos [...] e um certificado de pós-graduação de quatro cursos que enfatiza o estudo do conceito.

Esses esforços, naturalmente, concentram-se nos indiví- 
duos. Outra estratégia é se concentrar em níveis coletivos, como escolas e distritos escolares. Um projeto deste tipo está apenas começando, envolvendo a maioria dos professores que lidam com matemática em uma escola do ensino fundamental e médio em Calgary. Mais uma vez organizado em torno do estudo do conceito, este projeto de cinco anos está analisando o possível impacto na cultura da escola (Davis; Renert, 2014, p. 124).

A intenção em dispor de análises ainda mais refinadas acerca da variabilidade de realizações de um determinado conceito por professores aponta para o uso do Estudo do Conceito como um instrumento de controle que permitiria o exame minucioso daquilo que os professores efetivamente fazem ou podem vir fazer ao ministrarem aulas de Matemática. Mais uma vez, aos professores é dada toda a visibilidade, enquanto objeto e instrumento do poder disciplinar. Os professores são tomados como objeto quando se pretende registrar as diferentes formas que eles utilizam para comunicar um conceito matemático e, consequentemente, também são instrumento do poder, pois são eles que fornecem os dados para esses registros.

Como observamos, o poder disciplinar entra em exercício acionado pela estratégia que visa identificar o quê e como professores ensinam Matemática. Duas táticas são acionadas a fim de alcançar essa estratégia. Uma delas, associada aos discursos cognitivo-representacionais, é a tática da avaliação que, por meio do exame, realiza um escrutínio das práticas pedagógicas estabelecidas nos espaços escolares no intuito de qualificar e classificar tanto professores quanto estudantes. Por meio da tática da avaliação vê-se que o governo dos homens não se dá mais pela obediência, mas pela manifestação sobre aquilo que se é (Foucault, 1997). Já discursos sócio discursivos acionam a tática da colaboração na qual professores são convidados a participar de grupos colaborativos para que suas almas sejam exploradas, para que revelem as formas como realizam um determinado conceito matemático e sejam conduzidos entre diferentes ênfases, no sentido de ampliar o seu repertório sobre o conceito em estudo.

A participação de professores em atividades de exploração coletiva, tais como o Estudo do Conceito ou os testes padronizados de medidas individuais com fins homogeneizantes, acionam outras formas de expressão do poder: o poder pastoral e o biopoder. Michel Foucault discorre sobre o poder pastoral nos remetendo à figura do pastor de ovelhas da tradição judaico-cristã. Para o autor, o "[...] poder do pastor se exerce essencialmente sobre uma multiplicidade em movimento" (Foucault, 2008, p. 168). Assim, esse exercício de poder não ocorre sobre um lugar específico, mas sobre um rebanho, os professores, mais especificamente, sobre o rebanho em seu deslocamento, no movimento que o faz ir de um ponto a outro. Ou seja, o poder pastoral é posto em exercício por esses discursos quando eles conduzem os professores entre um tipo de conhecimento e outro, no caso de discursos cognitivo-representacionais; ou entre uma ênfase e outra, quando tratam de discursos sócio discursivos. 
Apesar de o discurso da Matemática específica para ensinar prever a participação de professores em grupos, o que se espera é que ao final cada um deles alcance a sua salvação individual. Ou seja, espera-se oferecer para cada um deles diferentes modos de lidar com a Matemática para fins de ensino, seja movendo-se entre um tipo de conhecimento e outro ou entre uma ênfase e outra. Por isso, é tão importante a integração do grupo, de modo que cada um permita que o outro saiba o que ele sabe, dirigindo-os, conduzindo-os mutuamente.

Em relação ao poder pastoral, a estratégia utilizada é a confissão, de modo que os professores, ao participarem de grupos de formação, confessem o que sabem e como ensinam determinado conceito. Ligada a essa estratégia tem-se a tática da movimentação na qual professores são levados a se deslocar entre um conhecimento e outro ou entre uma ênfase e outra de um conceito, a depender das afiliações epistemológicas as quais os discursos estão submetidos, a fim de alcançar o fim prometido: aprender uma Matemática específica para o ensino.

É com o surgimento da população, como um novo corpo social, que o biopoder entra em ação. $\mathrm{O}$ biopoder, diferente do poder soberano e do poder disciplinar (mas não separado destes), não se exerce sobre um corpo, mas sobre um corpo múltiplo, a população, por meio de regulamentações que buscam o governo da vida (Foucault, 1989).

Ao considerarmos o discurso da Matemática específica para ensinar, vemos este tipo de poder em ação quando subsidiam, independentemente de suas filiações epistemológicas, políticas públicas e programas de formação de professores de Matemática, por exemplo. Para ilustrarmos como esse poder se mostra em exercício em discursos cognitivo-representacionais, abaixo trazemos alguns trechos de estudos que sugerem como eles buscam regulamentar o governo da vida dos professores.

Esta descoberta fornece suporte para iniciativas de políticas destinadas a melhorar a realização matemática dos alunos, melhorando o conhecimento matemático dos professores (Hill; Rowan; Ball, 2005).

É improvável que as implementações curriculares em matemática forneçam os benefícios esperados para os alunos, se a orientação por escrito aos professores for interpretada e promulgada de maneira diferente das formas que os formuladores de políticas e os planejadores de currículo pretendem (Foster; Inglis, 2017).

As implicações incluem limitar o requisito mínimo a um diploma universitário de quatro anos e exigir que os professores ensinem vários níveis de ensino ao longo de um período de tempo (Ng, 2011).

Suas regulamentações visam determinar desde requisitos mínimos para ser professor de Matemática até níveis de proficiência esperados desses professores. Vê-se que é pretendido o controle de toda a população de professores de Matemática inclusive determinando que os 
mesmos devem seguir as orientações elaboradas por outrem sob pena de serem culpados pelo baixo desempenho de seus estudantes. Acreditam que ao regulamentar requisitos mínimos e medidas de qualidade é possível melhorar o desempenho dos estudantes em Matemática.

Por outro lado, discursos sócio discursivos ponderam sobre a dificuldade de apreender a natureza complexa, emergente, adaptativa e evolutiva da Matemática para o ensino. Entretanto, defendem que

[...] a comunidade [científica] tem a obrigação de trabalhar em conjunto para explorar, testar e criar novas possibilidades [...] [pois] muito poderia ser obtido se o ensino de matemática e a formação de professores incluíssem ênfases semelhantes a estudos de conceito" (Davis; Renert, 2014, p. 120)

Reconhecida a dificuldade em governar os professores por meio de políticas que se baseiam em resultados de avaliações em larga escala, discursos sócio discursivos propõem que este governo se dê a partir do acompanhamento da relação entre, por exemplo, o desempenho de estudantes em avaliações padronizadas e o seu interesse em seguir carreiras que requerem um conhecimento matemático.

[...] província de Alberta, no Canadá, tem comparativamente bom desempenho em testes de realização nacionais e internacionais em matemática. Mesmo assim, as matrículas em programas universitários relacionados à matemática estão em declínio constante há décadas. [...] Por mais importante que seja a realização pessoal, se os impactos do ensino não estão se registrando nos níveis social e cultural, questionamos sua eficácia (Davis; Renert, 2014, p. 120).

Além disso, destacam que é importante notar que existe uma forte relação entre a formação inicial e continuada de professores (Santos; Barbosa, 2016; Davis; Renert, 2014) e argumentam na defesa de projetos que combinem a articulação dessas formações em contexto de escolas parceiras nas quais o Estudo do Conceito possa ser desenvolvido (Davis; Renert, 2014).

O biopoder é exercido tendo como estratégia constituir políticas públicas educacionais e programas de formação de professores. Duas táticas são utilizadas, respeitando as afiliações epistemológicas de seus discursos: a tática da generalização acionada por discursos cognitivorepresentacionais e a tática da evolução acionada por discursos sócio discursivos. A tática da generalização, por meio de regulamentações (leis, diretrizes, resoluções, programas de formação), estabelece critérios gerais a serem adotados para a condução da conduta de professores. Estabelecem por meio de níveis de proficiência Matemática normatizações homogeneizantes. Por outro lado, a tática da evolução dispensa o uso de critérios gerais e é mobilizada quando propõe articulação entre a formação inicial e continuada de professores por acreditar que assim alcançariam uma mútua evolução, uma melhoria da população, do rendimento, a ponto de constituir um grupo de docentes com perfil profis- 
sional coeso e condizente com as demandas específicas relacionadas ao ensino de Matemática.

Observamos que o discurso da Matemática específica para ensinar põe em exercício diferentes tipos de poder que transitam entre a lógica individual e disciplinar (ao mobilizar estratégias e táticas afeitas aos poderes soberano e disciplinar) para a lógica governamental (ao mobilizar estratégias e táticas afeitas ao poder pastoral e ao biopoder). Esses poderes em exercício visam conduzir a conduta de professores de Matemática no sentido de: fazer viver uma Matemática específica para o ensino; identificar o que e como professores ensinam Matemática; confessar seus saberes e suas práticas de ensino; e constituir políticas públicas e programas de formação de professores.

\section{Efeitos do Poder ou Que Condutas Docentes?}

Mostramos, na seção anterior, que a condução da conduta de professores de Matemática só se alcança depois de se passar por poderes afeitos à soberania e à disciplina, utilizando "[...] mais táticas do que leis” (Foucault, 1989, p. 166). Quando voltamos o nosso olhar sobre os tipos de poder postos em funcionamento por esses discursos identificamos e descrevemos estratégias e táticas que constituem uma tecnologia de poder que tem sido endereçada aos professores de Matemática, a qual nomeamos como Tecnologia da Especificidade Matemática.

Essa tecnologia quer dar conta de um conjunto de práticas, munido de uma racionalidade estratégica que tem por objeto o ensino de Matemática, que permite mostrar como poder e saber se articulam para constituir professores de Matemática governáveis. A Tecnologia da Especificidade Matemática é acionada por discursos que sugerem a existência de uma Matemática que é específica para o ensino e, portanto, difere da Matemática requerida por outros profissionais.

Esses discursos divulgam condutas requeridas aos professores de Matemática orientadas pelo entendimento de que para ensiná-la é preciso saber uma Matemática específica, a qual seria alcançada no entrelaçamento de diferentes estratégias e táticas. Inicialmente, o professor é conduzido ao reconhecimento da soberania da Matemática frente a outros campos do saber, haja vista a necessidade de disponibilizar à população de professores domínios específicos de conhecimentos. Uma outra forma de conduzir os professores é expô-los ao exame, materializados em avaliações padronizadas, produzindo como efeito uma responsabilização sobre o desempenho de si e dos outros, pois quando um país, um estado ou uma escola não alcança os índices educacionais almejados, a responsabilidade recai sobre todos os professores.

É esperado também que os professores se mantenham em movimento, ou seja, que domine os diferentes conhecimentos requeridos para se ensinar Matemática e que saibam transitar entre eles à medida em que são requeridos na tarefa de ensinar. Além disso, espera-se que os professores integrem grupos para que possam ser conduzidos coletivamente à manutenção de uma Matemática específica para o ensino.

Educação \& Realidade, Porto Alegre, v. 46, n. 1, e98349, 2021. 
Por fim, os professores estão condenados a viver conduzidos por políticas públicas e/ou cursos de formação que visem subsidiar requisitos mínimos para ser professor de Matemática.

Neste sentido, inferimos que as condutas docentes almejadas pelo discurso da Matemática específica para ensinar perpassam pela constituição de um “[...] sujeito-professor(a)-de-Matemática” (Grilo; Barbosa; Maknamara, 2020, p. 3). Um sujeito munido de capacidades que atenderiam demandas específicas relacionadas ao ensino de Matemática, que perpassam pelo reconhecimento da existência diferentes tipos de conhecimentos ou ênfases conceituais e que podem ser adquiridas recorrendo à: diferenciação da Matemática frente a outras áreas; avaliação e colaboração do que se sabe; movimentação em busca da aprendizagem de novos conhecimentos, generalização e evolução de práticas de ensino.

\section{Considerações Finais}

Para alcançarmos o objetivo proposto neste ensaio, analisamos como o poder é posto em funcionamento pelo discurso da Matemática específica para ensinar. A nossa análise mostrou que esses discursos põem em exercício diferentes tipos de poder. Ao apresentarmos o poder soberano, discutimos como a Matemática precisa ser esquadrinhada antes de ser deslocada para fins de ensino. Ao tratarmos do poder disciplinar mostramos como o exame é utilizado como um instrumento que escrutina a vida de cada professor fornecendo o controle minucioso dos seus corpos. Transitando entre a lógica individual e disciplinar para a lógica governamental, vimos que o poder pastoral se mostra quando os discursos pretendem conduzir professores coletivamente guiandoos entre diferentes tipos de conhecimento ou entre diferentes ênfases de um conceito matemático e, ao analisarmos o biopoder, vimos que a condução dos professores se estabelece por meio de regulamentações que recaem sobre toda a categoria de professores de Matemática.

Esses poderes em ação, muitas vezes de forma mútua, mobilizam diferentes estratégias que são acionadas por diferentes táticas todas elas a serviço de uma tecnologia de poder que nominamos como Tecnologia da Especificidade Matemática. Foi através da análise dessa tecnologia que pudemos mostrar as condutas esperadas para os professores de Matemática disponibilizadas pelo discurso da Matemática específica para ensinar.

O governo destinado aos professores de Matemática visa conduzilos ao entendimento de que existiria uma Matemática específica para o ensino e que para alcançá-la o professor precisaria fazer viver uma Matemática que é específica para o ensino e deixar morrer uma Matemática que não é específica para o ensino. Além disso, esses professores seriam submetidos a um exame minucioso de suas práticas para oferecerem informações que seriam capazes de aperfeiçoar os caminhos a serem trilhados para aprimorar/evoluir a Matemática específica para o ensino e subsidiar regulamentações gerais sobre a formação de professores. 
Outros estudos são necessários para que se possa refletir sobre as múltiplas formas de resistência operacionalizadas pelas relações de poder que são mobilizadas pelo discurso da Matemática específica para ensinar. Para tanto, faz-se necessário interrogar as condições de existência dessas relações, direcionar o olhar para a ordem da estratégia e da luta contra as formas de sujeição do sujeito consigo mesmo e aos outros, que rechaçam, dentre outras coisas, a inquisição científica que busca determinar quem somos.

Recebido em 19 de novembro de 2019 Aprovado em 27 de novembro de 2020

\section{Notas}

1 Para Foucault (2014a) estas coisas são os homens em suas relações com tudo que o cerca: os recursos, os costumes, as formas de agir ou de pensar, as desgraças como a fome, a epidemia, a morte, etc.

2 Numa perspectiva foucaultiana os dois grupos são de ordem discursiva. O registro da palavra discursivo visa a demarcar que, ao operar com essa perspectiva, há um reconhecimento de que não existe uma única Matemática a priori a ser ensinada, mas que ela emerge das interações discursivas de uma prática social.

3 A referida pesquisadora foi premiada, em 2017, pela International Commission on Mathematical Instruction (ICMI), com a medalha Felix Klein, prêmio máximo de reconhecimento acadêmico na comunidade de Educação Matemática, como forma de reconhecimento a sua liderança e contribuição para a melhoria da prática de ensino de Matemática e formação de professores, com destaque ao desenvolvimento da teoria do Conhecimento Matemático para o Ensino (CME) (Fonte: <https://deborahloewenbergball.com/>).

4 A lista com as publicações pode ser encontrada em: <http://www.umich. edu/ lmtweb/research.html>.

5 Botsuana, Canadá (quatro províncias), Chile, Taipé Chinês, Geórgia, Alemanha, Malásia, Noruega, Omã, Filipinas, Polônia, Federação Russa, Cingapura, Espanha, Suíça, Tailândia e EUA.

6 Disponível em: <http://www.umich.edu/ lmtweb/>.

\section{Referências}

ADLER, Jill; HUILLET, Danielle. The Social Production of Mathematics for Teaching. In: SULLIVAN, Peter; WOOD, Terry (Org.). International Handbook of Mathematics Teacher Education: v. 1. Knowledge and Beliefs in Mathematics Teaching and Learning Development. Rotterdam: Sense Publishers, 2008. P. 195-222.

BALL, Deborah Loewenberg; BASS, Hyman. Making Mathematics Reasonable in School. In: KILPATRICK, Jeremy; MARTIN, Gary; SCHIFTER, Deborah (Org.). A Research Companion to Principles and Standards for School Mathematics. Reston: National Council of Teachers of Mathematics, 2003. P. 27-44.

BALL, Deborah; THAMES, Mark; PHELPS, Geoffrey. Content Knowledge for Teaching: what makes it special? Journal of Teacher Education, v. 59, n. 5, p. 389407, nov./dec. 2008.

Educação \& Realidade, Porto Alegre, v. 46, n. 1, e98349, 2021. 
BARWELL, Richard. Discursive Psychology as an Alternative Perspective on Mathematics Teacher Knowledge. ZDM Mathematics Education, v. 45, Issue 4, p. 595-606, jun. 2013.

CARRILLO, José; CLIMENT, Nuria; CONTRERAS, Luis Carlos; MUNÕZ-CATALÁN, María. Determining Specialized Knowledge for Mathematics Teaching. In: CONGRESS OF THE EUROPEAN SOCIETY FOR RESEARCH IN MATHEMATICS EDUCATION. v. 8, 2013, Ankara. Anais... Ankara, Turkey: M.E.T. University, 2013. P. 2985-2994.

CASTRO, Edgardo. Vocabulário de Foucault: um percurso pelos seus temas, conceitos e autores. 2 ed. Belo Horizonte: Autêntica, 2016.

CHARALAMBOUS, Charalambos; HILL, Heather. Teacher Knowledge, Curriculum Materials, and Quality of Instruction: unpacking a complex relationship. Journal of Curriculum Studies, v. 44, n. 4, p. 443-466, 2012.

DAVIS, Brent; RENERT, Moshe. The Math Teachers Know: profound understanding of emergent mathematics. NY: Routledge, 2014.

DELANEY, Seán. A Validation Study of the Use of Mathematical Knowledge for Teaching Measures in Ireland. ZDM Mathematics Education, v. 44, p. 427-441, 2012.

FIMYAR, Olena. Governamentalidade como Ferramenta Conceitual na Pesquisa de Políticas Educacionais. Educação \& Realidade, v. 34, n. 2, p. 35-56, maioago., 2009.

FOSTER, Colin; INGLIS, Matthew. Teachers' Appraisals of Adjectives Relating to Mathematics Tasks. Educational Studies in Mathematics, v. 95, n. 3, p. 283-301, 2017.

FOUCAULT, Michel. Microfísica do Poder. 8 ed. Rio de Janeiro: Graal, 1989.

FOUCAULT, Michel. Do Governo dos Vivos. In: FOUCAULT, Michel. Resumo dos Cursos do Collège de France (1970-1982). Rio de Janeiro: Jorge Zahar, 1997 P. 99-106.

FOUCAULT, Michel. Em Defesa da Sociedade: curso dado no College de France (1975-1976). São Paulo: Martíns Fontes, 1999a.

FOUCAULT, Michel. História da Sexualidade I: a vontade de saber. 13 ed. Rio de Janeiro: Edições Graal, 1999b.

FOUCAULT, Michel. Segurança, Território, População: curso dado no College de France (1977-1978). São Paulo: Martíns Fontes, 2008.

FOUCAULT, Michel. A Ordem do Discurso: aula inaugural do Collège de France, pronunciada em 2 de dezembro de 1970. 24 ed. São Paulo: Edições Loyola, 2014a. FOUCAULT, Michel. Vigiar e Punir. Petrópolis: Vozes, 2014b.

FOUCAULT, Michel. Arqueologia do Saber. 8 ed. Rio de Janeiro: Forense Universitária, 2016.

GRILO, Jaqueline de Souza Pereira; BARBOSA, Jonei Cerqueira; MAKNAMARA, Marlécio. Discurso da Matemática Específica para Ensinar e a Produção do Sujeito 'Professor(a)-de-Matemática'. Ciência \& Educação, Bauru, v. 26, e20040, 2020.

HAROUN, Ramzi; NG, Dicky; ABDELFATTAH, Faisal; ALSALOULI, Misfer. Gender Difference in Teachers' Mathematical Knowledge for Teaching in the Context of Single-Sex Classrooms. Int J of Sci and Math Educ, v. 14 (Suppl 2), p. S383-S396, 2016. 
HILL, Heather. Mathematical Knowledge of Middle School Teachers: implications for the No Child Left Behind Policy initiative. Educational Evaluation and Policy Analysis, n. 29, p. 95-114, 2007.

HILL, Heather; BALL, Deborah. Learning Mathematics for Teaching: results from California's mathematics professional development institutes. Journal of Research in Mathematics Education, n. 35, p. 330-351, 2004.

HILL, Heather; ROWAN, Brian; BALL, Deborah. Effects of Teachers' Mathematical Knowledge for Teaching on Student Achievement. American Educational Research Journal, v. 42, n. 2, p. 371-406, 2005.

HILL, Heather; SCHILLING, Stephen; BALL, Deborah. Developing Measures of Teachers' Mathematics Knowledge for Teaching. Elementary School Journal, v. 105, p. 11-30, 2004.

HOOVER, Mark; MOSVOLD, Reidar; BALL, Deborah; Loewenberg; LAI, Yvonne. Making Progress on Mathematical Knowledge for Teaching. Mathematics Enthusiast, v. 13, n. 1-2, p. 3-34, apr. 2016.

HUILLET, Danielle. Mathematics for Teaching: an anthropological approach and its use in teacher training. For the Learning of Mathematics, v. 29, n. 3, p. 4-10, 2009.

KWON, Minsung; THAMES, Mark; PANG, Jeongsuk. To Change or not to Change: adapting mathematical knowledge for teaching (MKT) measures for use in Korea. ZDM Mathematics Education, v. 44, p. 371-385, 2012.

MAKNAMARA, Marlécio; PARAÍSO, Marluce. Pesquisas Pós-Críticas em Educação: notas metodológicas para investigações com currículos de gosto duvidoso. Revista da FAEEBA - Educação e Contemporaneidade, v. 22, n. 40, p. 41-53, 2013.

MENEGHETTI, Francis. O que é um ensaio-teórico? Revista de Administração Contemporânea, v. 15, n. 2, p. 320-332, abr. 2011.

MORIEL JUNIOR, Jeferson; WIELEWSKI, Gladys. Base de Conhecimento de Professores de Matemática: do genérico ao especializado. Revista de Ensino, Educação e Ciências Humanas, v. 18, n. 2, p. 126-133, 2017.

MOSVOLD, Reidar; FAUSKANGER, Janne. Teachers' Beliefs about Mathematical Knowledge for Teaching Definitions. International Electronic Journal of Ma-

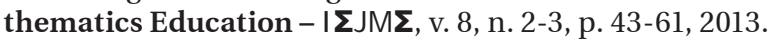

NG, Dicky. Indonesian Primary Teachers' Mathematical Knowledge for Teaching Geometry: implications for educational policy and teacher preparation programs. Asia-Pacific Journal of Teacher Education, v. 39, n. 2, p. 151-164, 2011. NÍ RÍORDÁIN, Máire, PAOLUCCI, Catherine; O’ DWYER, Laura. An Examination of the Professional Development Needs of Out-of-Field Mathematics Teachers'. Teaching and Teacher Education, v. 64, p. 162-174, 2017.

PHELPS, Geoffrey; KELCEY, Benjamin; LIU, Shuangshuang; JONES, Nathan. Informing Estimates of Program Effects for Studies of Mathematics Professional Development Using Teacher Content Knowledge Outcomes. Evaluation Review, v. 40, p. 383-409, 2016.

POURNARA, Craig. Can Improving Teachers' Knowledge of Mathematics Lead to Gains in Learners' Attainment in Mathematics? South African Journal of Education, v. 35, n. 3, 2015.

SANTOS, Graça Luzia Dominguez; BARBOSA, Jonei Cerqueira. Um Modelo Teórico de Matemática para o Ensino do Conceito de Função a Partir de um Estudo com Professores. Revista Iberoamericana de Educación Matemática, n. 48, p. 143-167, diciembre 2016. 
SCHILLING, Stephen; BLUNK, Merrie; HILL, Heather. Test Validation and the MKT Measures: Generalizations and Conclusions. Measurement - Interdisciplinary Research and Perspectives, v. 5, n. 2-3, p. 118-127, 2007.

SHULMAN, Lee. Knowledge and Teaching: Foundations of the New Reforms. Harvard Educational Review, v. 57, n. 1, feb. 1987.

TATOO, Maria (Org.). Teacher Education and Development Study in Mathematics (TEDS-M): policy, practice, and readiness to teach primary and secondary mathematics in 17 countries: Technical Report. Amsterdan: IEA, 2013.

TATTO, Maria; BURN, Katharine; MENTER, Ian; MUTTON, Trevor; THOMPSON, Ian. Learning to Teach in England and the United States: the evolution of policy and practice. London: Routledge, Taylor \& Francis Group, 2018.

TCHOSHANOV, Mourat. Relationship Between Teacher Knowledge of Concepts and Connections, Teaching Practice, and Student Achievement in Middle Grades Mathematics. Educational Studies in Mathematics, v. 76, p. 141-164, 2011.

VEIGA-NETO, Alfredo. Coisas do Governo... In: RAGO, Margareth; ORLANDI, Luiz; VEIGA-NETO, Alfredo (Org.). Imagens de Foucault e Deleuze: ressonâncias nietzschianas. Rio de Janeiro: DP\&A, 2002. P. 13-34.

VILLADSEN, Kaspar. Tecnologia Versus Ação: uma falsa oposição atribuída a Foucault nos estudos organizacionais. Revista O\&S, Salvador, v. 21, n. 71, p. 643660 , out./dez. 2014

Jaqueline de Souza Pereira Grilo é professora do Departamento de Educação da Universidade Estadual de Feira de Santana (UEFS) e do Programa de Pós-Graduação em Educação da UEFS.

ORCID: http://orcid.org/0000-0002-0408-047X

E-mail: jspgrilo@uefs.br

Jonei Cerqueira Barbosa é professor da Faculdade de Educação da Universidade Federal da Bahia (UFBA). Docente do Programa de Pós-Graduação em Educação e do Programa de Pós-Graduação em Ensino, Filosofia e História das Ciências, ambos na mesma instituição. Pesquisador Produtividade CNPq.

ORCID: http://orcid.org/0000-0002-4072-6442

E-mail: jonei.cerqueira@ufba.br

Editora-responsável: Beatriz Vargas Dorneles

Este é um artigo de acesso aberto distribuído sob os termos de uma Licença Creative Commons Atribuição 4.0 Internacional. Disponível em: <http:// creativecommons.org/licenses/by/4.0>. 